American Journal of Pharmacology and Toxicology 5 (2): 89-94, 2010

ISSN 1557-4962

(C) 2010 Science Publications

\title{
A Prospective Evaluation of Antihypertensive Medications Safety and Efficacy in United Arab Emirates Private Hospitals
}

\author{
Muaed Jamal Alomar and Claire Caroline Strauch \\ Department of Clinical Pharmacy, Faculty of Pharmacy and Health Sciences, \\ Ajman University of Science and Technology Network, Fujairah, P.O. Box 7826, \\ UAE Fujairah, United Arab Emirates
}

\begin{abstract}
Problem statement: Hypertension is one of the most important risk factors for heart and cardiovascular diseases in the United Arab Emirates (UAE). Evaluation of the safety and efficacy of antihypertensive medications in UAE private hospitals is important. The importance arises because of the high prevalence of hypertension in this multicultural region. This study evaluated the use of antihypertensive medications among patients suffering from hypertension alone or with other medical conditions. Approach: A prospective observational study was conducted using 400 hypertensive inpatients randomly selected from private hospitals to evaluate the safety and efficacy of antihypertensive medications in UAE. Patients were diagnosed to have hypertension with or without other medical conditions and both males and females were included in the study. The study included all nationalities that live in the UAE. All data were collected either from patient's files, interviewing physicians, nurses or by interviewing the patients during the period of admission. Results: Analysis of the 400 patients revealed that most of them were male (87.5\%), Arabs (45\%), Indians and Pakistan $(37.5 \%)$ and Asians (10\%). A correlation exists between certain factors and the prevalence of hypertension like nationality, age, gender and occupation. Family history of hypertension is important to determine the genetic inheritance of hypertension, $82 \%$ of hypertensive patients with or without other medical conditions had a family history of hypertension (23\% of them had fathers suffering from hypertension, $23 \%$ had mothers with hypertension and 36.4\% having both parents with hypertension. There was no statistical significant difference in DBP between female and male patients (mean DBP; $79 \mathrm{Vs} 82.9 \mathrm{mmHg}$ respectively, $\mathrm{p}=0.076$ ), but there was a difference in the mean SBP between females and males (mean SBP $149 \mathrm{Vs} 138 \mathrm{mmHg}$ respectively, p-value $=0.044$ ). The reported adverse drug reactions during the study were headache, dizziness and peripheral edema, shortness of breath, nausea, gastrointestinal tract problems and muscle cramps. Conclusion: Many factors contribute to the increase in blood pressure; family history and life style were considered the most important factors. Combination therapy appeared to be associated with high rate of adverse drug reactions; enough to warrant either decreasing the number of medications or changing the medication. More effort from all medical professionals and patients was needed in order to minimize the risk of uncontrolled hypertension in the UAE.
\end{abstract}

Key words: Hypertension, UAE, antihypertensive, evaluation, cardiovascular

\section{INTRODUCTION}

According to the World Health Organization (2003) Hypertension is one of the most important risk factors for heart and cardiovascular diseases. Hypertension can lead to damage of the brain, heart and kidney, resulting in renal insufficiency, hemorrhagic and/or thrombotic stroke, myocardial infarction, sudden death, heart failure. Thus according to Stamler et al.
(1993) and Ruilope and Segura (2002) and European Society of Hypertension-European Society of Cardiology (2003) monitoring blood pressure can significantly reduce the risk of cerebrovascular and cardiovascular complications especially in patients with diabetes mellitus and renal insufficiency (Stamler et al., 1993; Ruilope and Segura, 2002).

In MEDLAB Magazine (2006) the epidemiological Study of Hypertension in the United Arab Emirates

Corresponding Author: Muaed Jamal Alomar, Department of Clinical Pharmacy, Faculty of Pharmacy and Health Sciences, Ajman University of Science and Technology Network, Fujairah, P.O. Box 7826, UAE Fujairah, United Arab Emirates Tel: 00971507157641 Fax: 0097192223176 
(NESH-UAE) (the project was initiated to understand the extent of prevalence of hypertension in the country) showed that from a total of 8,820 UAE citizens surveyed, the overall prevalence of hypertension was $33.1 \%$ of the total population.

The percentage of hypertension among UAE citizens is significantly high enough to oblige medical professionals and decision makers to spend more efforts in order to reduce the incidence of hypertension among all age groups, especially elderly. The pharmacotherpaeuic approach for the treatment of hypertension is influenced by the type of the accompanied medical problems; e.g., renal failure, diabetes mellitus, throb embolic disorders. Certain medications have a better impact on some patients than others. Liau et al. (2005) have shown that olmesartan for example appeared to be more potent and has a more rapid antihypertensive effect than Losartan in the treatment of mild-to-moderate hypertension in Chinese patients. Valcarcel et al. (2006) demonstrated that longacting calcium antagonists such as Amlodipine have been shown to be effective and well tolerated among both young and elderly people. UAE is a multinational country which makes it a good place to study the differences of drug safety and efficacy among different nationals. The objectives of this study are to evaluate the safety and efficacy of antihypertensive medications in patients admitted to five UAE private hospitals (in Abu Dhabi; The Capital of UAE).

\section{MATERIALS AND METHODS}

A prospective observational study was conducted using 400 hypertensive inpatients randomly selected according to certain inclusion and exclusion criteria from five private hospitals in the UAE (Abu Dhabi). Patients were diagnosed to have hypertension with or without other medical conditions, both males and females and those with age between 20-80 years old were included in the study. The study included all nationalities that live in the United Arab Emirates (Arabs, Asians, Indians, Chinese, Westerners and Africans). All patients had a history of hypertension for a period between 10-15 years. Exclusion criteria include pregnancy, cancer and aids patients and patients under the age of 20 years old and over 80 years old.

The study was conducted in four months starting from January-April in 2010. All hypertensive patients who fulfill the inclusion criteria and admitted to one of the five private hospitals in Abu Dhabi in the period of the study were included in the selection of the sample. Simple random technique was used to select the patients.

Data collection include patient's file number, age, gender, nationality, weight, height, marital status, blood pressure upon admission, daily morning blood pressure, number of children, smoking experience, alcohol consumption, work load, history of present illness, family history, other medical problems, physical activity and exercise experience, current medications and medication history, adverse drug reactions and the time of occurrence. All data are collected either from patient's files, interviewing physicians, nurses and patients.

Data on the development of adverse drug reactions were collected from patients' interview and confirmed by physicians and nurses. Efficacy data were measured according to the response to medications by monitoring blood pressure readings on daily bases.

Data was collected and analyzed using SPSS ver.16.0 statistical program. The analysis was done in both descriptive and comparative ways. ANOVA was used to compare differences in blood pressure between different age groups.

\section{RESULTS}

The analysis of the 400 patients included in this study revealed that most of them were male $(87.5 \%)$, Arabs (45\%), Indians and Pakistan (37.5\%) and Asains (10\%). The mean Body Mass Index (BMI) was 28, mean Diastolic Blood Pressure (DBP) was $82 \mathrm{mmHg}$ and mean Systolic Blood Pressure (SBP) was $139 \mathrm{mmHg}$ during hospitalization. Most participants were married (90\%), had children $(82.5 \%)$ and non smokers $(52.5 \%)$. $17.5 \%$ of patients were smokers and $20 \%$ were exsmokers. All smokers were men and 50\% of them were Indians and Pakistan. 33.3\% drink alcohol and 67.7\% don't drink alcohol. Most alcohol drinkers were men (92\%), Indians and Pakistan (67\%), Asians (33\%), no alcohol drinking among Arab patients. About $82.5 \%$ of patients had stressful jobs. Patient's disease condition and coexisting medical problems are shown in Table 1.

Among all patients, only $32.5 \%$ do physical exercise, $85 \%$ of those who do physical exercise are not smokers. None of the nine patients with both hypertension and diabetes were doing any kind of exercise, only one out of five patients complaining of hypertension, diabetes and dyslipidaemia were exercising. $50 \%$ of plain hypertensive patients and $47 \%$ of hypertensive patients with dyslipidaemia were exercising.

Family history of hypertension is important to determine the genetic inheritance of hypertension, in this study $82 \%$ of hypertensive patients with or without other medical conditions had a family history of hypertension $(23 \%$ of them had fathers suffering from hypertension, $23 \%$ had mothers with hypertension and $36.4 \%$ having both parents with hypertension. 
Am. J. Pharm. \& Toxicol., 5 (2): 89-94, 2010

Table 1: Distribution of medical conditions Vs patients

\begin{tabular}{|c|c|c|c|c|c|c|c|c|c|c|c|c|c|c|}
\hline \multirow[b]{2}{*}{ Main diseases } & \multicolumn{14}{|c|}{ Additional diseases } \\
\hline & A & $\mathrm{C}$ & $\mathrm{CH}$ & M & $\mathrm{O}$ & CAD & $\mathrm{N}$ & $\mathrm{K}$ & DVT & $\mathrm{H}$ & IBS & A & $\mathrm{L}$ & $\mathrm{T}$ \\
\hline Hypertension & 0 & 10 & 0 & 0 & 0 & 20 & 60 & 10 & 10 & 0 & 0 & 0 & 0 & $\overline{110}$ \\
\hline $\begin{array}{l}\text { Hypertension + Dyslipidemia } \\
\text { No. of patients }\end{array}$ & 20 & 0 & 0 & 10 & 0 & 10 & 80 & 0 & 10 & 0 & 10 & 10 & 0 & 150 \\
\hline Hypertension + Dyslipidemia+Diabetis Mellitus & 0 & 0 & 0 & 0 & 10 & 0 & 3 & 1 & 0 & 0 & 0 & 0 & 0 & 50 \\
\hline Hypertension + Diabetes Mellitus & 10 & 0 & 10 & 0 & 0 & 20 & 30 & 0 & 0 & 10 & 0 & 0 & 10 & 90 \\
\hline
\end{tabular}

A: Asthma; C: Cancer; CH: Cholecystitis; M; Meat allergy; O: Odynophagea; CAD: Coronary Artery Disease; N: No additional diseases; K: Kidney stone; DVT: Deep Vein Thrombosis; H: Hyperurecaemia; IBS: Inflammatory Bowel Syndrome; A: Allergic rhinitis; L: Lung infections; T: Total

Table 2: Age distribution

\begin{tabular}{lcc}
\hline Age range & Frequency & Percentage \\
\hline $20-29$ & 20 & 5.0 \\
$30-39$ & 60 & 15.0 \\
$40-49$ & 150 & 37.5 \\
$50-59$ & 120 & 30.0 \\
$60-69$ & 20 & 5.0 \\
$70-79$ & 30 & 7.5 \\
Total & 400 & 100.0 \\
\hline
\end{tabular}

Table 3: List of medications given during the study

\begin{tabular}{llll}
\hline Medication & Dose $(\mathrm{mg})$ & Frequency & NOP \\
\hline Valsartan & 160 & Once daily & 120 \\
Amlodipine & $5-10$ & Once daily & 80 \\
Rosuvastatin & 10 & Once daily & 70 \\
Aspirin & 100 & Once daily & 190 \\
Fluvastatin & 80 & Once daily & 60 \\
Simvastatin & $5-40$ & Once daily & 120 \\
Atrovastatin & $20-40$ & Once daily & 80 \\
Clopidogrel & 75 & Once daily & 70 \\
Gliclazide & $30-80$ & Once-twice daily & 60 \\
Losaran & $50-100$ & Once daily & 20 \\
Lisinopril & $10-20$ & Once daily & 40 \\
Esmoprazole & 20 & Once daily & 40 \\
Felodipine & $5-10$ & Once daily & 20 \\
Fenofibrate & 200 & Once daily & 10 \\
Lercanidipine & 10 & Once daily & 50 \\
Hydrochlorothiazide & 25 & Once daily & 150 \\
Moxonidine & 0.4 & Once daily & 20 \\
Metformine & $500-1000$ & Twice daily & 50 \\
Fosinopril & $5-20$ & Once daily & 30 \\
Perindopril & 5 & Once daily & 20 \\
Atenolol & $25-100$ & Once daily & 80 \\
Hydroxizine & 10 & Once daily & 10 \\
Pravastatin & 40 & Once daily & 40 \\
Allopurinol & 300 & Once daily & 10 \\
Glimipride & $2-4$ & Once-twice daily & 30 \\
Amiloride & 10 & Once daily & 10 \\
Bisoprolol & 5 & Twice daily & 10 \\
Frusemide & 40 & Twice daily & 20 \\
Carvedilol & $3-12.5$ & Once-twice daily & 20 \\
\hline NOP N & 5 & &
\end{tabular}

NOP: Number Of Patients taking the medication

Most patients were in the 40-49 year old age group (37.5\%), followed by the 50-59 year old age group $(30 \%)$, detailed age distribution is shown in Table 2.

Medical therapy: Angiotensin converting enzyme inhibitors, Angiotensin II antagonists, Calcium channel blockers, beta blockers, Antiplatelets and Lipid lowering medications were given to the patients during hospitalization. These medications, their doses and frequency of use are shown in Table 3.

Forty patients (10\%) had Diastolic Blood Pressure (DBP) between 100-109 $\mathrm{mmHg}$ and their Systolic Blood Pressure (SBP) between 140-160 mmHg. Some of the patients were given Lisinopril $10 \mathrm{mg}$ once daily and others were giving Valsartan $160 \mathrm{mg}$ once daily plus Hydrochlorothiazide $25 \mathrm{mg}$ once daily, Atenolol $25 \mathrm{mg}$ once daily and the last group of the forty was given Bisoprolol $5 \mathrm{mg}$ once daily with Frusemide $40 \mathrm{mg}$ twice daily. The Atenolol and Bisoprolol patients were diabetic and they were taking hypoglycemic medications. All of the patients were males, age between 30-60 years old, most of them their BMI was between 28-35, respiration rates were high (19-20 BPM), all were married, had children and twenty of them were smokers and alcohol drinkers.

Ten Indian female patient $(2.5 \%)$ with plain hypertension had a very high SBP $(228 \mathrm{mmHg})$ and DBP $(124 \mathrm{mmHg})$, they were a smoker, an alcohol drinker, singles, BMI 30 and had a family history of hypertension. They were taking Amlodipine $10 \mathrm{mg}$ once daily, Hydrochlorothiazide $25 \mathrm{mg}$ once daily, Amiloride $10 \mathrm{mg}$ once daily and Simvastatin $10 \mathrm{mg}$ once daily. The patients were suffering from headache and dizziness. Twelve patients $(3 \%)$ had severe hypotension while taking Perindopril $5 \mathrm{mg}$ once daily and Atenolol $25 \mathrm{mg}$ once daily. they also suffered from headache.

There were hundred and ten male patients (27.5\%) with a DBP between $90-99 \mathrm{mmHg}$ and a SBP between 120-185 mmHg. Alcohol consumption, BMI, nationality, gender and marital status had no specific impact on blood pressure readings in these patients. Hundred patients (25\%) had a DBP between $70-79 \mathrm{mmHg}$ and a SBP between $100-140 \mathrm{mmHg}$. All of these patients were married, aged between 30-60 years old, $70 \%$ of them were non smokers, $50 \%$ don't drink alcohol, $40 \%$ suffered from headache, $40 \%$ fatigue, $20 \%$ dizziness, $10 \%$ edema, $20 \%$ bad breath, $20 \%$ muscle cramps, 20\% SOB, 20\% loss of appetite, 10\% GIT problems and $20 \%$ numbness. Thirty male patients had low DBP (60-69 $\mathrm{mmHg}$ ) and ten patients had very low DBP (50-59 mmHg) and low SBP (111 mmHg). 
Am. J. Pharm. \& Toxicol., 5 (2): 89-94, 2010

Table 4: Medication therapy Vs adverse drug reactions

\begin{tabular}{|c|c|c|c|c|c|c|}
\hline $\mathrm{D}$ or $\mathrm{DC}$ & NOPUD & ADR1 (no.) & ADR2 (no.) & ADR3 (no.) & ADR4 (no.) & ADR5 (no.) \\
\hline$\overline{\mathrm{V}, \mathrm{Ro}, \mathrm{As}, \mathrm{Si}, \mathrm{Am}, \mathrm{Hy}}$ & 9 & $\mathrm{~F}$ & $\mathrm{E}$ & & & \\
\hline V, Ro, As, Si, C, Hy & 11 & $\mathrm{~N}$ & M & LOA & LOSD & \\
\hline $\mathrm{V}, \mathrm{Ro}, \mathrm{As}, \mathrm{Si}, \mathrm{Hy}$ & 8 & $\mathrm{G}$ & & & & \\
\hline $\mathrm{V}, \mathrm{As}, \mathrm{Fl}, \mathrm{Ro}$ & 9 & $\mathrm{~F}$ & $\mathrm{~N}$ & LOA & $\mathrm{CP}$ & \\
\hline V, Fl, Hy & 10 & $\mathrm{~F}$ & $\mathrm{Nu}$ & Di & $\mathrm{Ba}$ & \\
\hline V, Fl, Hy, Le & 10 & $\mathrm{He}$ & & & & \\
\hline $\mathrm{V}, \mathrm{Am}, \mathrm{Hy}, \mathrm{At}$ & 10 & $\mathrm{Di}$ & $\mathrm{Ba}$ & $\mathrm{M}$ & & \\
\hline V, Hy & 10 & $\mathrm{Di}$ & $\mathrm{N}$ & & & \\
\hline As, Ro, C & 10 & $\mathrm{He}$ & $\mathrm{F}$ & & & \\
\hline As, Ro, Am, Si & 10 & $\mathrm{G}$ & $\mathrm{He}$ & & & \\
\hline As, Ro, At, Al, Hy & 10 & G & $\mathrm{F}$ & $\mathrm{M}$ & & \\
\hline As, Si, At, C & 7 & $\mathrm{He}$ & LOA & PU & & \\
\hline As, $\mathrm{Si}, \mathrm{C}$ & 9 & $\mathrm{~N}$ & & & & \\
\hline As, Am, Si, Fl & 10 & $\mathrm{He}$ & $\mathrm{F}$ & & & \\
\hline As, Si, Fl, Le, Mo, Hy & 10 & $\mathrm{He}$ & $\mathrm{Nu}$ & $\mathrm{E}$ & G & $\mathrm{Dm}$ \\
\hline As, At & 10 & $\mathrm{He}$ & $\mathrm{N}$ & $\mathrm{Vd}$ & & \\
\hline As, At, C & 10 & $\mathrm{~F}$ & & & & \\
\hline As & 40 & $\mathrm{He}$ & G & $\mathrm{F}$ & & \\
\hline $\mathrm{Am}, \mathrm{Si}, \mathrm{Hy}$ & 10 & $\mathrm{He}$ & $\mathrm{Di}$ & & & \\
\hline $\mathrm{Am}$ & 30 & $\mathrm{He}$ & $\mathrm{F}$ & $\mathrm{E}$ & M & \\
\hline $\mathrm{Si}$ & 10 & $\mathrm{He}$ & $\mathrm{F}$ & & & \\
\hline $\mathrm{Si}, \mathrm{C}, \mathrm{Le}$ & 11 & M & & & & \\
\hline Hy & 12 & $\mathrm{~F}$ & $\mathrm{Fe}$ & & & \\
\hline
\end{tabular}

There was no statistical significant difference in DBP between female and male patients (mean DBP; $79 \mathrm{Vs} 82.9 \mathrm{mmHg}$ respectively, $\mathrm{p}=0.076$ ), but there was a difference in the mean SBP between females and males (mean SBP 149 Vs $138 \quad \mathrm{mmHg}$ respectively, $\mathrm{p}$-value $=0.044)$.

When DBP was compared between different age groups using one way ANOVA, there was no statistically significant difference in blood pressure readings ( $\mathrm{p}$-value $=0.52$ ), but when SBP is compared between age groups, the difference was statistically significant ( $\mathrm{p}$-value $=0.019$ ). The age group 20-29 had the highest SBP readings (mean SBP $206 \mathrm{mmHg}$ ) and the lowest was in the 30-39 age group (mean SBP 128 $\mathrm{mmHg}$ ). There was no statistically significant difference in SBP and DBP among all the smoking groups $(\mathrm{p}$-value $=046$ and 0.24 respectively). Also there was no difference in DBP and SBP between different nationality groups (Arab, Asian, Indians and Pakistan), $\mathrm{p}$-value $=0.29$ and 0.35 respectively) .

Tolerability: The most common adverse drug reactions were headache, dizziness, peripheral edema, SOB, nausea, GIT problems and muscle cramps. Table 4 illustrates all of the adverse drug reactions to every single medication or combination therapy used by the patients.

The percentage of ADR occurrence in all patients is variable; headache $(37.5 \%)$, fatigue $(37.5 \%)$, numbness $(10 \%)$, dizziness $(12.5 \%)$, bad breath $(5 \%)$, edema $(12.5 \%)$, muscle cramps $(15 \%)$, nausea $(17.5 \%)$, loss of appetite $(7.5 \%)$, GIT problems $(17.5 \%)$, SOB $(12.5 \%)$, chest pain $(12.5 \%)$ and cough $(12.5 \%)$.

\section{DISCUSSION}

According to U.S. government estimates based on a total UAE population of 4.4 million, more than $75 \%$ of the population (about 3.4 million) is aged between 15-64 years. The population is dominated by males (3 millions) with only 1.4 million females. UAE citizens constitute approximately $20 \%$ of the population. The rest are foreign workers, predominantly from South and Southeast Asia (approximately 60\% of the population). The remainder of the expatriate population includes a significant number of other Arabs.

Male participation shows the big gap between the number of the two sexes and the dominance of male gender in the country. The average people in UAE are overweight (average BMI 28), across sectional survey carried out in the UAE reflects the dominance of overweight and obesity, the overall prevalence of obesity was estimated to be around $35.7 \%$ among the UAE nationals, which seems to be affected mainly by genetic and lifestyle factors (Musaiger et al., 2003).

The incidence of white coat hypertension was higher in overweight and obese patients than in normal 
weight subjects in a study evaluating the impact of obesity on 24 ambulatory blood pressure and hypertension. It also illustrated that systolic and diastolic blood pressure were significantly correlated with BMI (Kotsis et al., 2005).

The average SBP and DBP were in the acceptable range after hospital treatment. Hypertension is highly prevalent among UAE residents regardless of the nationality and culture. Bad treatment approaches and lack of awareness may be the reason behind the increase in the incidence of hypertension (Elshahat, 1999).

Lack of physical exercise among hypertensive patients accompanied with the presence of co-morbid diseases is clearly seen in this study which may require health care providers to spend more effort and time on the counseling regarding the benefits of changing lifestyle and more physical activity.

Low physical activity, low income, having more than three children and smoking have shown a high contribution in the development of hypertension among UAE residents according to study done in UAE (Sabri, 2005).

Also genetic inheritance of hypertension play a crucial role in developing hypertension, $82 \%$ of participants had one or both of their parents suffering from hypertension. Many studies have documented the effect of hereditary factors on the development of hypertension and this can be seen in the prevalence of hypertension among blacks more than whites and the different degrees of hypertension between different races or tribes (Opie et al., 2005).

Even though some studies in the UAE show that there are differences in the treatment among national and expatriates in the country; this study shows that the differences in DBP and SBP readings among all nationalities were not statistically significant but this is most probably due to the fact that all patients enrolled in this study were treated in the same private hospital and all of them were wealthy enough to afford better treatment (Abdishakur et al., 2006).

In regard to drug therapy and selection of the best medication for the right patient. In this study Atenolol and Bisoprolol were given for hypertension to patients with both hypertension and diabetes mellitus. A prospective study of 12550 adults concluded that beta blockers have increased the incidence of diabetes mellitus by $28 \%$ and it was higher than those without medication (Todd, 2000).

Another study showed that the combination of beta blockers and Thiazide diuretics have increased the incidence of new onset diabetes mellitus by $32 \%$ (Dahlof et al., 2005).

On the other hand, Carvedilol improved metabolic syndrome and had no negative effect on glycemic control when compared to Metoprolol in a randomized control trial (Bakris et al., 2004).

It is not simple to conclude that beta blockers should be avoided if patients have diabetes mellitus, but caution is mandatory in this situation (Padwal and Laupacis, 2004).

Alcohol drinking, high BMI, marriage and smoking could be the reason behind the lack of response of high blood pressure to medications.

In the eleven patients who had blood pressure readings between $90-99 \mathrm{mmHg}$ there was no specific treatment used among them, Amlodipine, hydrochlorothiazide, Atenolol, Valsartan and some other medications were used but not all together, the lack of response may be due to patient incompliance or incomplete lifestyle modifications and bad Pharmacotherapeutic choices.

Drug interactions and adverse drug reactions: Aspirin and Clopidogrel was given as combination to five patients, many recent studies support the use of this combination for the prevention of thrombosis especially in diabetes mellitus patients. In a comparative study between aspirin and Clopidogrel and aspirin alone given to diabetic hypertensive patients, it has been found that the combination therapy induced a better Antiplatelet effect than aspirin alone (Serebruany, 2008).

There is no primary literature to support the use of Simvastatin and Rosuvastatin as combination therapy. Duplication in this situation could happen which will lead to an increased risk of adverse drug reactions since both medications are from the same therapeutic group with a similar mechanism of action.

About $67.5 \%$ of the patients involved in this study developed ADRs, $45 \%$ of the patients developed more than one side effect and $15 \%$ of the patients have three or more side effects. In order to minimize the percentage of ADR occurrence among hypertensive patients, serious measures should be taken to ensure the best choice of Pharmacotherapeutic alternatives, clinical Pharmacoinformatic systems for ADR prediction and prevention could offer great assistance in achieving this goal (Alomar et al., 2008).

\section{CONCLUSION}

Combination therapy appears to be associated with high rate of adverse drug reactions; enough to warrant either decreasing the number of medications or changing the medication. One of the most important factors which affect patient compliance and drug adherence is the presence of adverse drug reactions. Managing hypertension requires multi disciplinary 
teams and full cooperation with patients. Drug counseling, lifestyle changes, avoiding smoking and alcohol drinking are issues changing hypertensive treatment in the UAE.

\section{REFERENCES}

Abdishakur, M.A., J.D. Nico, S. Abouchacra, J.Y. Pathan and E.N. Obineche, 2006. Under-treatment and under diagnosis of hypertension: A serious problem in the United Arab Emirates. BMC Cardiovasc. Disord., 6: 24. DOI: 10.1186/14712261-6-24.

Alomar, M.J., A.A. Hourani and S.A. Sulaiman, 2008. Proposal for the development of adverse drug reaction prediction model. Am. J. Pharmacol. Toxicol., 3: 190-197.

Bakris, G.L., V. Fonseca and R.E. Katholi, 2004. Metabolic effects of carvedilol Vs metoprolol in patients with type 2 diabetes mellitus and hypertension. A randomized controlled trial. J. Am. Med. Assoc., 292: 2227-2236. DOI: 10.1001/jama.292.18.2227

Dahlof, B., P.S. Sever, N.R. Poulter, H. Wedel and D.G. Beevers et al., 2005. Prevention of cardiovascular events with an antihypertensive regimen of amlodipine adding perindopril as required versus atenolol adding bendroflumethiazide as required, in the AngloScandinavian Cardiac Outcomes Trial-Blood Pressure Lowering Arm (ASCOT-BPLA): A multicentre randomized controlled trial. Lancet, 366: 895-906. DOI: $10.1016 / \mathrm{S} 0140-$ 6736(05)67185-1

Elshahat, Y.M., 1999. Hypertension in UAE citizenspreliminary results of a prospective study, Saudi J. Kidney Dis. Transpl., 10: 376-381. http://www.sjkdt.org/text.asp?1999/10/3/376/37247

European Society of Hypertension-European Society of Cardiology, 2003. Guidelines for the management of arterial hypertension. Eur. Heart J., 24: 1601-1610. DOI: 10.1016/S0195-668X(03)00347-6

Kotsis, V., S. Stabouli, M. Bouldin, A. Low and S. Toumanidis, 2005. Impact of obesity on 24-hour ambulatory blood pressure and hypertension. Hypertension, 45: 602-607. DOI: 10.1161/01.HYP.0000158261.86674.8e

Liau, C.S., C.M. Lee, S.H. Sheu, K.C. Ueng and T.C. Su et al., 2005. Efficacy and Safety of Olmesartan in the Treatment of Mild-to-Moderate Essential Hypertension in Chinese Patients. Clin Drug Invest., 25: 473-479. http://www.medscape.com/viewarticle/507360
Opie, L.H., K. Yackoob and M.D. Seedat, 2005. Hypertension in Sub-Saharan African populations. circulation. J. Am. Heart Assoc., 112: 3562-3568. DOI: 10.1161/CIRCULATIONAHA.105.539569

MEDLAB Magazine, 2006. Content. http://www.arabhealthonline.com/upl_images/Issue 6-article3.pdf\%20

Musaiger, A.O., O.L. Lloyd, A.B. Bener and S.M. Al-Nyadi, 2003. Life style factors associated with obesity among male students in the United Arab Emirates. Nutr. Food Sci., 33: 145-147. DOI: 10.1108/00346650310488480

Padwal, R. and A. Laupacis, 2004. Antihypertensive therapy and incidence of type 2 diabetes. A systematic review. Diabetes Care, 27: 247-255. DOI: $10.2337 /$ diacare.27.1.247

Ruilope, L.M. and J. Segura, 2002. Renal protection by antihypertensive therapy. Curr. Hypertens Rep., 4: 324-328. PMID: 12117461

Sabri, S., 2005. Correlation between hypertension and income distribution among United Arab Emirates population. Med. J. Malaysia, 60: 416-425. PMID: 16570702

Serebruany, V.L., 2008. Effects of clopidogrel and aspirin in combination versus aspirin alone on platelet activation and major receptor expression in diabetic patients: Plavix use for treatment of diabetes. Am. Heart J., 155: 93.e1-93.e7. http://www.medscape.com/viewarticle/569091

Stamler, J., R. Stamler and J.D. Neaton, 1993. Blood pressure, systolic and diastolic and cardiovascular risks: US population data. Arch. Intern. Med., 153: 598-615. PMID: 8439223

Todd, W.G.R., 2000. Hypertension and antihypertensive therapy as risk factors for type 2 diabetes mellitus. N. Engl. J. Med., 342: 905-912. http://content.nejm.org/cgi/content/abstract/342/13/ 905

Valcarcel, Y., R. Jimenez, V. Hernandez, R. Aristegui and A. Gil, 2006. Efficacy and safety of amlodipine. Clin. Drug. Invest., 26: 125-133. http://www.medscape.com/viewarticle/528305

World Health Organization, (WHO), 2003. International society of hypertension writing group. 2003 World Health Organization (WHO)/International Society of Hypertension (ISH) statement on management of hypertension. J. Hypertens, 21: 1983-1992. 